\title{
A Novel Natural History Phenomenon: A Free-living Marine Flatworm (Polycladida) Attached to a Common Asian Toad (Duttaphrynus melanostictus)
}

Md. Fazle Rabbe ${ }^{1}$, Deponkor Kumar Roy ${ }^{2}$, Nur Mohammad ${ }^{3}$, Fahmida Tasnim Liza ${ }^{4}$, Mandira Mukutmoni ${ }^{4}$, Md. Mahabub Alam ${ }^{1}$, Aleya Begum ${ }^{4}$, and M. Firoj Jaman ${ }^{1}$

${ }^{1}$ Wildlife Biology, ${ }^{2}$ Genetics and Molecular Biology, ${ }^{3}$ Fisheries, ${ }^{4}$ Parasitology, Department of Zoology, University of Dhaka, Dhaka 1000, Bangladesh (fazlerabbedu@gmail.com)

$\mathrm{O}$ 14 March 2018, during a nocturnal field survey of agricultural land on Nijhum Dwip Island, Noakhali, Bangladesh $\left(22^{\circ} 02^{\prime} 22.0^{\prime \prime} \mathrm{N}, 91^{\circ} 00^{\prime} 07.8^{\prime \prime} \mathrm{E}\right)$, we found a Marine Flatworm (Platyhelminthes: Turbellaria: Polycladida) attached to the dorsum of a Common Asian Toad (Duttaphrynus melanostictus) (Fig. 1). The toad was not calling and we found no other anurans in the vicinity.

The Common Asian Toad is widely distributed in Bangladesh, where it inhabits diverse habitats, including agri- cultural fields (Hasan et al. 2014; Khan 2015). Polyclads are carnivorous predators of marine invertebrates and live in all types of marine environments, with only three species known to occur in limnic or brackish waters (Galleni et al. 1980; Bahia Maceira 2017). We identified the worm to order in the laboratory based on morphological characteristics described in Galleni et al. (1980). It was $12.5 \mathrm{~mm}$ in length and $9 \mathrm{~mm}$ in width; the body was transparent, flattened, leaf-like, roughly oval in shape and brownish in color; the digestive tract was
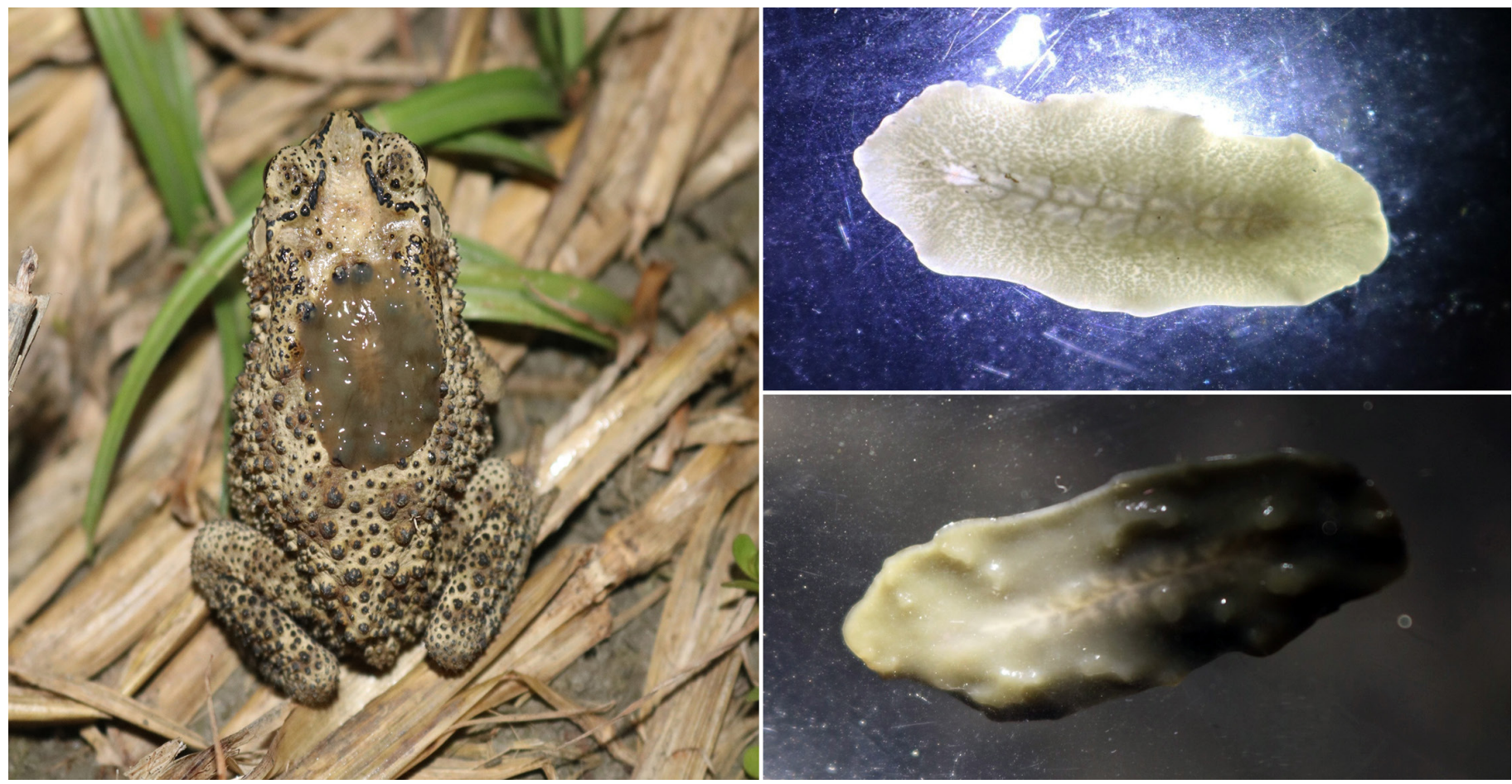

Fig. 1. A free-living Marine Flatworm (Polycladida) attached to the dorsum of a Common Asian Toad (Duttaphrynus melanostictus) on Nijhum Dwip Island, Noakhali, Bangladesh (left); dorsal view of the polyclad with eyespots anteriorly (upper right); ventral view of the polyclad with pseudotentacles (lower right). Photographs by Md. Fazle Rabbe. 
elongated with seven intestinal branches, the first six of which were fully segmented whereas the last branch was partially segmented; two oval eyespots ( $2 \mathrm{~mm}$ from the anterior border and $1 \mathrm{~mm}$ apart) were evident near the first branch of the intestine. A sticky mucous facilitated attachment to the toad, and ventral pseudotentacles enabled it to move quickly (about 3 sec to leave the body of the toad).

Tidal flow through a canal connected with the sea can flood the low-lying agricultural field on Nijhum Dwip. This might have allowed this polyclad to enter the field through saltwater flowing through a canal connected with the sea. The specimen was taken into the laboratory and preserved for further examination.

We cannot explain how or why the polyclad became attached to the toad. However, to the best of our knowledge, the attachment of a polyclad to a toad is described nowhere else in the literature, leading us to conclude that our observation is a novel natural history phenomenon.

\section{Acknowledgments}

We thank Professor Dr. Niamul Naser for managing fieldwork on Nijhum Dwip Island.

\section{Literature Cited}

Bahia Maceira, J. 2017. Polycladida Biodiversity and Systematics: An Integrative Approach. Unpublished Ph.D. Dissertation, Faculty of Biology, LudwigMaximilian University, Munich, Germany.

Galleni, L., P. Tongiorgi, E. Ferrero, and U. Salghetti, 1980. Stylochus mediterraneus (Turbellaria: Polycladida), predator on the mussel Mytilus galloprovincialis. Marine Biology 55: 317-326.

Hasan, M.K., M.M.H. Khan, and M.M. Feeroz. 2014. Amphibians and Reptiles of Bangladesh - A Field Guide. Arannayk Foundation, Dhaka, Bangladesh.

Khan, M.A.R. 2015. Wildlife of Bangladesh: Checklist-cum-guide. M.J. Alam, Chayabithi, Dhaka, Bangladesh. 